This item was submitted to Loughborough's Research Repository by the author.

Items in Figshare are protected by copyright, with all rights reserved, unless otherwise indicated.

\title{
Attitudes to building services component reuse in the UK healthcare sector
}

PLEASE CITE THE PUBLISHED VERSION

http://dx.doi.org/10.1108/02632779810235663

\section{PUBLISHER}

(c) MCB University Press (now Emerald)

\section{VERSION}

AM (Accepted Manuscript)

\section{LICENCE}

CC BY-NC-ND 4.0

\section{REPOSITORY RECORD}

Thomson, Derek S., John R. Kelly, and Roy S. Webb. 2019. "Attitudes to Building Services Component Reuse in the UK Healthcare Sector". figshare. https://hdl.handle.net/2134/9657. 
This item was submitted to Loughborough's Institutional Repository (https://dspace.lboro.ac.uk/) by the author and is made available under the following Creative Commons Licence conditions.

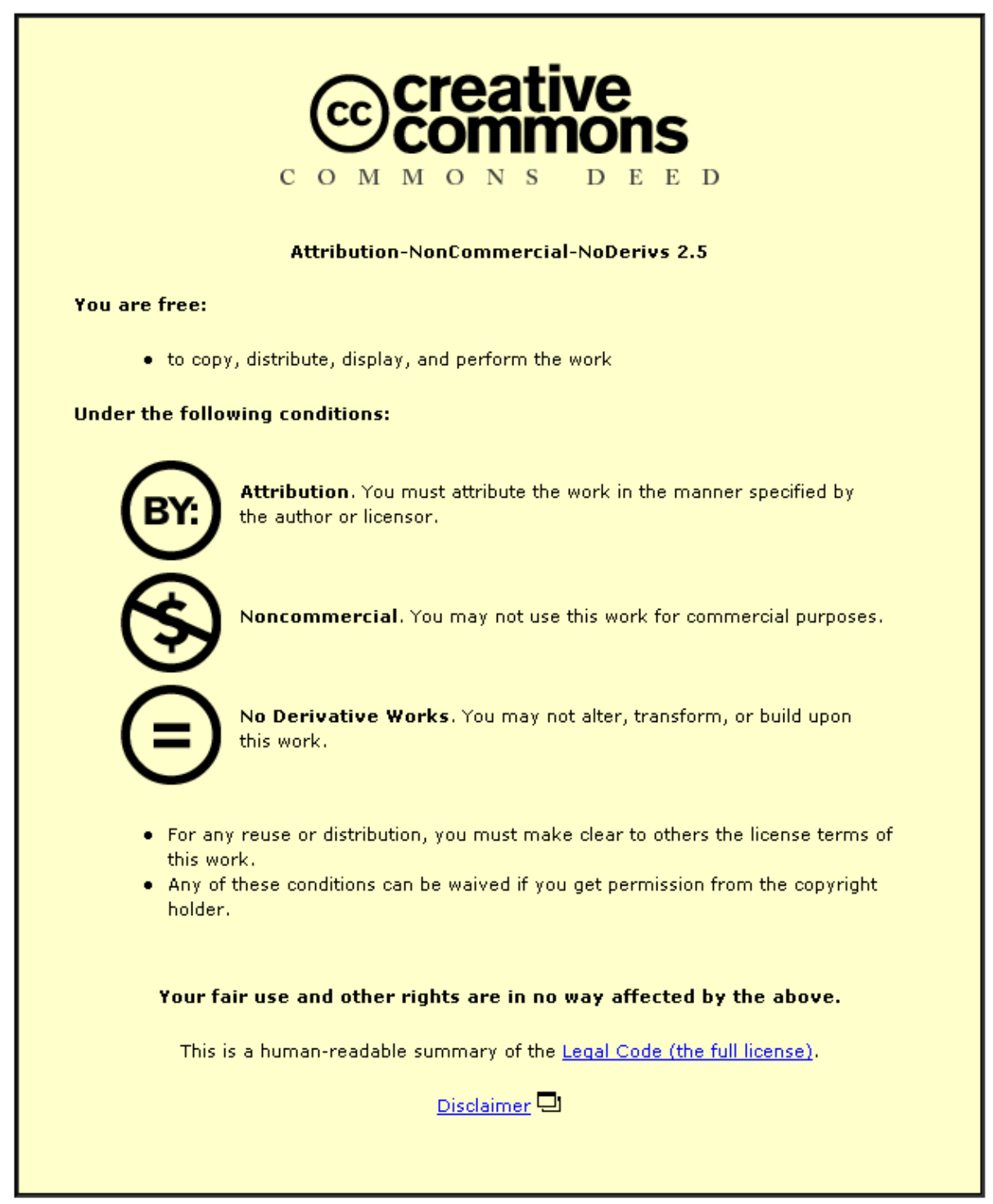

For the full text of this licence, please go to: http://creativecommons.org/licenses/by-nc-nd/2.5/ 


\title{
An Exploration of Component Reuse in the Achievement of Adaptable Building Services Installations
}

\author{
Derek S. Thomson, John R. Kelly, Roy S. Webb
}

\begin{abstract}
The response of many organisations to instability in their operating environment has been the development of flexible means of performing core function creating demand for flexible supporting building space. While architectural solutions to providing such space have existed for many years, their servicing remains problematic. These difficulties are manifested in the rising cost of services alteration resulting from a change in space function. The inability of services installations to be constructed in a flexible manner has prompted a study of reusable building services components as a possible means to increase services installation adaptability by reducing alteration costs. Focusing on the UK national health service, this paper presents a survey of trends in organisational function, their estate implications and the extent to which facilities managers can control or plan estate responses to frequent core function revision. Current services component reuse practices are reviewed and those component and process attributes that are conducive to disassembly and refurbishment are identified. It is concluded that reusable services components will achieve the required services installation adaptability, but the technical feasibility and economic viability of their use remains to be determined.
\end{abstract}

\section{Keywords:}

building services; national health service; adaptability; functional obsolescence; reuse; overhauling; guarantees

\section{Introduction}

Technological advancement and rising consumer expectations have acted over the last decade to diminish stability of the operating environment of many organisations. To remain competitive in their increasingly dynamic circumstance, businesses are achieving greater flexibility in the performance of their core function. Organisations in many sectors have adopted new working practices such as the non-fordist approach and outsourcing non-core functions which, by increasing the flexibility with which their core function is performed, have placed new demands on supporting building requirements. These flexible organisations must be supported by an estate providing flexible usable space to ensure that buildings can continually respond to changes in organisational function by readily accommodating changes in the use of building spaces. 
Architectural solutions for the provision of flexible space are well established, allowing facilities managers to change building space use without significant structure or fabric alteration (Duffy, et. al., 1993). Open plan office space is a common solution of this type. As the evolution of user function necessitates more extensive servicing of buildings, changes in space use increasingly necessitate alteration of supporting building services installations. This paper investigates the theory that although services installation design is evolving, current solutions can only be considered interim as their short-comings are manifested in the cost of frequent services installation alteration. Given that it is not possible to design flexible services installations there is therefore, a latent demand to develop means of designing, constructing and using services installations in an adaptable manner. The Department of Building Engineering and Surveying is undertaking an EPSRC pilot study to investigate the technical feasibility and economic viability of adaptable building services installations.

Previous work (Webb, et. al., 1997a, 1997b) has suggested that reusable building services components will increase the adaptability of both new and existing services installations. As building use patterns become more dynamic, the duration of individual space applications will diminish. Accordingly, supporting services installations will be adapted more often, causing components to be installed for time periods significantly shorter than their physical or economic life. Given that current services alteration practices typically invoke removal of existing components and replacement with new, the value of discarded components will rise as periods of use diminish. Reducing the duration of use will result in discarded components embodying a greater extent of under-utilised physical life and un-depreciated capital. At some point, the value of these reusing-enabling attributes will become greater than the value of constituent component materials (represented by component scrap value). Under such circumstances, component sale for reuse, rather than sale for disposal as scrap, will realise the higher residual value of these potentially reusable functionally obsolete components. The cost of services installation alteration will thereby be reduced, increasing installation adaptability.

To ensure that functionally obsolete components can be reused, however, it may be necessary to revise their design and methods of use. Component types currently reused, if any, must be identified to determine which of their characteristics contribute to their reusability. To identify these characteristics and to appraise construction industry response to this proposal, a survey was carried out.

\section{Survey Objectives}

The objectives of the survey were to:

1. confirm that commercial organisations are increasingly adopting a flexible approach to their core function.

2. identify and review current building services reuse practices.

3. review the responses of industry to proposed reusable services components.

4. identify those component attributes that increase reusability. 


\section{Survey Methodology}

To undertake this survey, the size of the construction industry necessitated review of representative constituent organisation categories. It was also necessary to focus on a particular building user type to permit review of function. The UK national health service, as a public body, presents a readily approachable, knowledgeable and well defined client body. This review determined the demands placed upon their facilities managers

Three groups were selected to represent the construction industry. These were: consultant building services engineers, specialist services installation contractors and building services component manufacturers. NHS trusts were selected to represent clients because, in their role as healthcare providers, they use the majority of the NHS estate. It was recognised that many determinants of NHS trust function, such as rising patient expectations and changing medical technology and practice, are unique to the healthcare sector. The survey remains valid, however, because NHS trusts respond in the same manner as commercial organisations to influences that affect their core function provision and require changes of space use in the short term.

Due to the size and complexity of survey group populations, the survey was administered in a postal questionnaire format. Standard questionnaire development methodology was used. An individual targeted questionnaire was administered to each group and developed using an iterative pilot interview approach. In the case of NHS trusts, the availability of accurate information detailing the full extent of this population permitted inclusion of the whole population, i.e. the group was not sampled. Samples of the three remaining populations were randomly selected from membership directories of their associated professional bodies or trade associations. Given this use of random sampling, the number of usable questionnaire returns provided a sufficient measure of survey validity and representativity. Table I presents these return proportions.

\begin{tabular}{lccc}
\hline Surveyed Population & Number Sent & \multicolumn{2}{c}{ Usable Returns } \\
& & Frequency & Percent \\
\hline NHS Trust clients & 485 & 102 & $21 \%$ \\
Consultant Services Engineers & 279 & 29 & $10 \%$ \\
Services Installation Contractors & 299 & 39 & $13 \%$ \\
Services Component Manufacturers & 341 & 42 & $12 \%$ \\
\hline
\end{tabular}

\section{TABLE I: Return Proportions for Each Surveyed Group}

Although low, the above return proportions are typical for an unsolicited questionnaire and were sufficient for analysis to commence. The substantially higher proportion of returns received from the NHS trusts could be considered representative of trusts' perceived relevance of this work to their needs.

\section{Implications of Core Function Revision on Building Use Patterns}

To predict facilities managers' estate reactions to revisions in the activity of building users, it was necessary to review NHS trusts' anticipation of future revision in their core function. This review provided an indication of the need for more reusable building services components. Table II presents the results of this analysis. 


\begin{tabular}{lcccccc}
\hline $\begin{array}{l}\text { Envisaged likely future change in } \\
\text { provision of healthcare services }\end{array}$ & $\begin{array}{c}\text { Change likely to } \\
\text { occur in the short } \\
\text { term }\end{array}$ & $\begin{array}{c}\text { Change likely to } \\
\text { occur in the long } \\
\text { term }\end{array}$ & $\begin{array}{c}\text { Change likely to } \\
\text { occur in both the } \\
\text { short and long } \\
\text { term }\end{array}$ \\
& Freq. & Percent & Freq. & Percent & Freq. & Percent \\
\hline a. $\quad \begin{array}{l}\text { Adoption of purchaser-led } \\
\text { demand response }\end{array}$ & 25 & $\mathbf{6 9 \%}$ & 8 & $22 \%$ & 3 & $8 \%$ \\
b. $\begin{array}{l}\text { Development of ability to } \\
\text { instigate provision of new } \\
\text { services and market them on the }\end{array}$ & 18 & $\mathbf{5 5 \%}$ & 13 & $39 \%$ & 2 & $6 \%$ \\
$\begin{array}{l}\text { internal market } \\
\text { Specialisation via creation of } \\
\text { centres of excellence }\end{array}$ & 19 & $32 \%$ & 36 & $\mathbf{6 0 \%}$ & 5 & $8 \%$ \\
d. $\begin{array}{l}\text { Specialisation via transfer of } \\
\text { non-core services to secondary } \\
\text { environment }\end{array}$ & 10 & $39 \%$ & 16 & $\mathbf{6 2 \%}$ & 0 & $0 \%$ \\
e. $\begin{array}{l}\text { General downsizing in range of } \\
\text { healthcare services provided }\end{array}$ & 9 & $31 \%$ & 15 & $\mathbf{5 2 \%}$ & 5 & $17 \%$ \\
\hline
\end{tabular}

TABLE II: Selected Anticipated Future Revision to NHS Trust Core Function

As illustrated by Table II, NHS trusts seek to establish more flexible working practices in the short term while, in the long term, they intend to establish a more stable function. These trends are represented by the bold figures in Table II. While planned long term changes appear to reduce the need for reusable building services components, it was observed they will also reduce the size of NHS trusts' estate. It will therefore become necessary to optimise the use of residual estate, increasing the need to respond effectively to change in use demands. It was considered, therefore, that demand for reusable building services components will also exist in the long term.

Review of planned function revision was completed by appraising drivers of change to estate provisions. If the nature of these drivers prohibits their control by NHS trust facilities managers, then the need for adaptable building services installations constructed from reusable components will be substantiated. The survey identified the most prominent core function drivers as the need to respond to healthcare purchasers' strategies and the associated need to respond to changes in delivered healthcare services. In addition, trusts must revise their supporting estate to accommodate changing medical practices, to optimise the use of existing assets and to minimise their operating costs. It is evident, therefore, that the most prominent factors causing estate revisions originate outside of trust organisations and, accordingly, were considered to be beyond their control. Hence it is necessary for NHS trusts to establish flexible means of providing space to ensure that they can respond to any changes in these external influences. It was consequentially concluded that those factors necessitating revisions to the NHS estate also create additional demand for the proposed reusable building services components.

\section{Patterns of Estate Space Use Change}

The types of building services component most likely to become functionally obsolete and consequentially suitable for reuse are those supporting building spaces that are frequently changed in use. To identify these components it was necessary to model patterns of space use in the NHS estate. Traditionally, the NHS estate has been represented by two elements; that supporting healthcare delivery in the primary, community-based, environment and that 
supporting healthcare delivery in the secondary, hospital-based, environment. The provision of predominantly acute healthcare services in the secondary environment was hypothesised to cause it to exhibit the greatest extent of building services and the greatest frequency of changes in use. Although this model of the NHS estate is widely accepted and embodied in guidance literature published for use by NHS facilities managers (Department of Health, 1996a, 1996b), it was found to be incomplete.

In addition to the dichotomous estate elements comprising the primary and secondary environments an additional, 'core', element was identified by NHS trusts' survey responses. This element, containing spaces such as operating theatres and intensive therapy units, is the most heavily serviced and the least often changed. Excluding office and administration space, ward and general clinical areas were found to exhibit the greatest frequency of space use change. Day care centres and out-patient clinics, located at the primary-secondary estate interface, are less often changed. Spaces comprising the primary healthcare estate were found to exhibit the least changes in use. This model of estate composition and element use change frequency is presented in Figure 1.
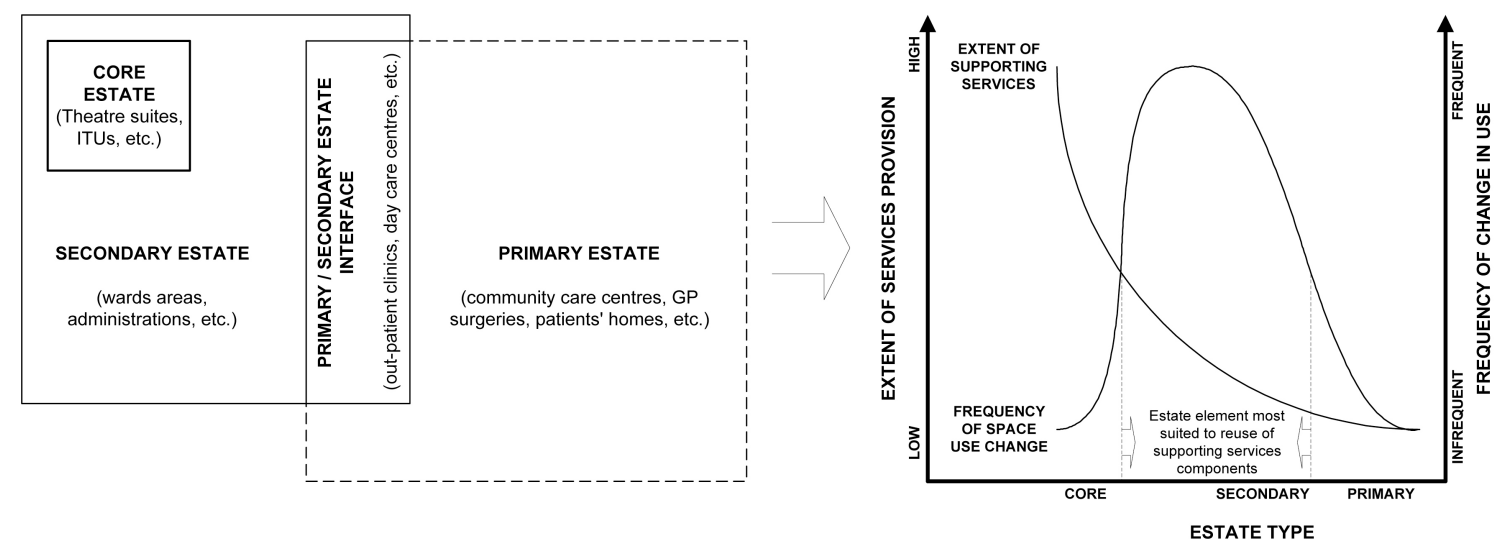

\section{FIGURE 1: Model of the NHS Estate Derived from Assessment of Space Use Change Frequency and Servicing Extent}

The elements of the NHS estate that would most advantageously be supported by services installations incorporating reusable components were identified by simultaneously plotting the frequency of space use change and usable space servicing requirements. Hence it was determined that this proposal would yield greatest benefit if those components found in the services installations supporting ward and clinical accommodation were designed to be more reusable.

\section{Current Services Component Reuse Practices}

Before more reusable building services components can be produced, current services component reuse practices must be characterised. This understanding will provide an insight into those component and reuse process characteristics facilitating reuse and which may require attention to permit the introduction of widespread component reuse. Despite the general perception that component reuse is not widely implemented, $83 \%$ of responding NHS trusts have experience of this practice and $72 \%$ of client's consultant engineers have implemented 
component reuse in their designs. Only about half (49\%) of specialist services installation contractors, however, have installed reused components suggesting that clients are carrying out reuse themselves or that a comparatively smaller number of specialist contractors have a greater experience of reuse.

Although the above proportions suggest that component reuse is widespread, only $21 \%$ of NHS trusts will invest in reused components originating from outside their own estate. It is apparent, therefore, that organisational boundaries present a significant barrier to reuse implementation. When a component is transferred from one organisation to another, historical knowledge of its operation is lost, causing potential re-users to be uncertain regarding the component's ability to perform. The reuse practices of other industries show that these concerns can be overcome if components are overhauled and performance guaranties issued.

Further impediments to component reuse, which must be addressed before reuse will become widespread, were found to include the inability of NHS trusts to identify sources of components suitable for reuse, concerns regarding the economic viability of reuse and the inability of many component designs to be upgraded resulting in their technological obsolescence. In addition, services engineers stated that their implementation of component reuse is impeded by the inability of reused components to satisfy current legislation and relative inefficiency of reused components when compared to new equivalents. Implementation of reuse by installation contractors is restricted by the limited availability of guaranties, concerns regarding the economic viability of reuse and the imposed restrictions of clients and engineers.

\section{The Implementation of Services Component Reuse}

Before components can be redesigned to improve their reusability, it was necessary to determine the component design attributes that contribute to reusability. This was achieved by identifying the component types currently reused most often and reviewing their design characteristics. Any commonality in these characteristics suggested their contribution to component reusability.

\section{Identification of Reuse-Enabling Component Characteristics}

Services engineers and installation contractors were asked to identify the components they reuse most often. These were found to be air conditioning plant, pumps and pumps sets, electrical power and distribution equipment and boilers. The reuse-enabling characteristics possessed by these components fall into two categories; those which contribute to component durability and maintainability and those that allow components to be physically moved between installation.

The above types of component are likely to be well maintained during their prior installation; in some instances periodic testing is imposed by legislatory obligations. Such maintenance reduces the extent of overhauling or reconditioning required prior to reuse, thereby improving the economics of the process. The need to accommodate rigorous maintenance necessitates that components are physically durable and, due to the materials used in their fabrication, they tend to possess a long life. In addition, the non-bespoke nature of many of these components aids identification within and isolation from their surrounding installations. This simplifies recovery and re-installation processes. The design of these components exhibited a number of 
commonalties including varying extents of modularisation, standardisation and prefabrication; design approaches whose contribution to component reusability remains to be fully investigated. It was further noted that these components tend to be of high value, increasing the probability of reuse being economically viable.

\section{The Need for a Support Industry}

As identified above, reusable components must be overhauled before reuse to facilitate guarantee of performance. Reuse practices in other industries are often characterised by subsidiary industries which perform this function (Siuru, 1990, Regan and McCall, 1997). Establishment of a similar support industry to overhaul reusable components is therefore proposed. Construction industry response to this proposal was surveyed to determine likely membership of this sector, the anticipated function of which is presented in Figure 2.

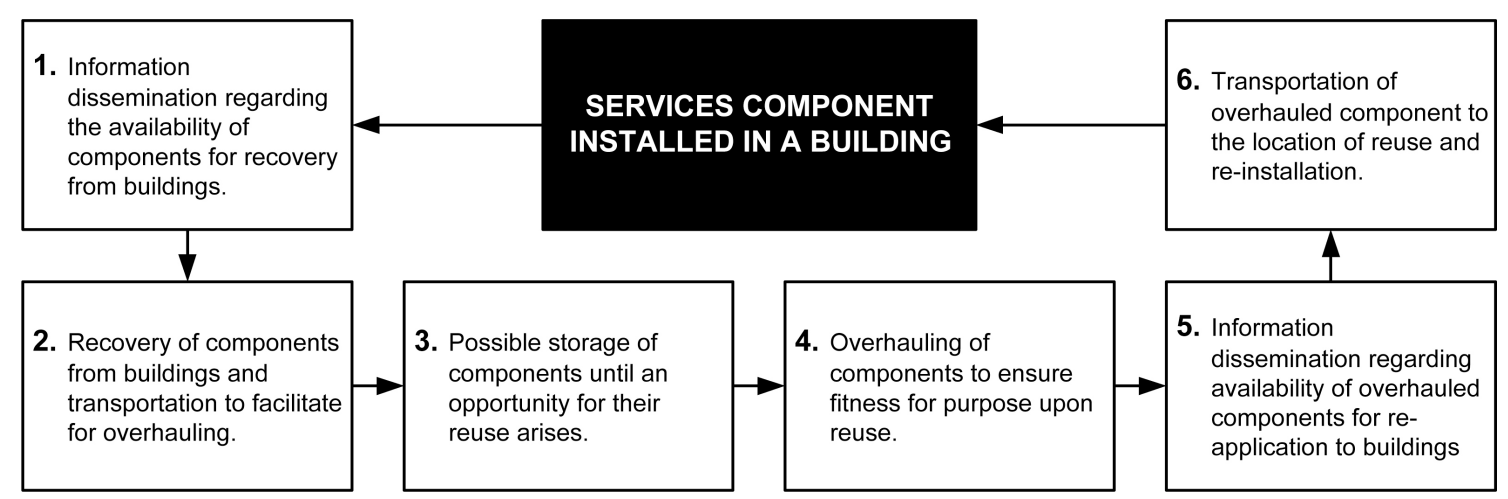

FIGURE 2: Suggested Reusable Component Reuse Implementation Mechanism

In other industries, these support sectors comprise original equipment manufacturers, specialised remanufacturers or certified agents of OEMs. These organisations possess the specialised tools and knowledge required for overhauling (Lund, et. al., 1980, Regan and McCall, op. cit.). Because component manufacturers were considered best suited to forming this support industry their willingness to implement various aspects of its function were surveyed. The results are presented in Table III. 


\begin{tabular}{llc}
\hline & $\begin{array}{l}\text { Component manufacturers' component reuse implementation } \\
\text { measure }\end{array}$ & $\begin{array}{c}\text { Proportion of component } \\
\text { manufacturers willing to } \\
\text { implement measure }\end{array}$ \\
\hline a. $\quad \begin{array}{l}\text { Willing to manufacture more reusable building services } \\
\text { components }\end{array}$ & $88 \%$ \\
b. $\quad \begin{array}{l}\text { Willing to overhaul components of own original manufacture } \\
\text { prior to their reuse }\end{array}$ & $86 \%$ \\
c. $\quad \begin{array}{l}\text { Willing to overhaul components of originally manufactured by } \\
\text { others prior to their reuse }\end{array}$ & $43 \%$ \\
d. $\quad \begin{array}{l}\text { Willing to provide guarantee with overhauled components } \\
\text { (assuming willingness to manufacture reusable components) }\end{array}$ & $79 \%$ \\
e. $\quad \begin{array}{l}\text { Perceived viability of proposed component reuse supporting } \\
\text { industry sector }\end{array}$ & $45 \%$ \\
\hline
\end{tabular}

TABLE III: Willingness of Services Component Manufacturers to Implement Provision Required for Function of Component Overhauling Support Industry

The willingness of component manufacturers to undertake most functions of the support industry confirms their suitability for membership. Their unwillingness to overhaul the components of other manufacturers is to be expected given the variability in building services component design solutions and their unfamiliarity with such components. The presence of more generic knowledge, perhaps embodied by a new organisation type, in this support industry would therefore be beneficial. Demonstration of the need for reusable components and their potential technical and economic feasibility will increase perceptions of this industry's viability. Overall, this support industry was considered viable although it was accepted that it may, in fact, be represented by an additional service of component manufacturers. The suitability of component manufacturers to this function was confirmed by further survey findings. $97 \%$ of responding services engineers stated that they considered OEMs to be suited to overhauling, although $72 \%$ also considered OEMs' certified agents to be capable. Services maintenance contractors were originally proposed for membership of this new industry sector, however only $50 \%$ of surveyed services engineers agreed with this suggestion.

\section{Conclusions and Further Work}

Previous work has determined that organisational function is trending towards the achievement of greater flexibility in core function performance. Influences determining healthcare provider function in the UK national health service have the same effect as those present in the commercial sector. The healthcare sector was therefore selected to provide a focused environment for development of this work. It has previously been established that increasingly dynamic organisations must be supported by flexible building space. The problematic nature of servicing such flexible space caused the development of reusable building services components to be proposed as a means to reduce installation alteration costs and thereby increase installation adaptability. A survey of the implications of this proposal was undertaken.

An understanding of component types most likely to become available for reuse was obtained by identifying NHS estate elements most often changed in use. The generally accepted model of the NHS element comprising the dichotomous primary and secondary environment elements was found to be incomplete. A further, 'core', element was identified by the survey. This element, while being the most heavily serviced, is changed the least often. The secondary spaces 
(predominantly ward and clinical accommodation) immediately surrounding this core were found to be changed in use most often and services installations supporting these spaces, although not as extensive as those supporting the core element, were considered likely to realise the greatest benefit from incorporation of reusable building services components.

Planned revisions to NHS trusts' core function were reviewed and, in both the short and the long term, found to increase the need for flexible supporting building space and associated reusable building services components. To establish the basis for development of such components, current building services component reuse practices were reviewed.

It was found that organisations responsible for implementing reuse are impeded in their function when a component is transferred from one organisation to another as historical knowledge of previous component performance, reliability, etc. is lost. It is proposed that this restriction can be overcome by guaranteeing reused component performance. To do this, however, overhauling or other reconditioning prior to reuse is required. It was therefore additionally proposed that a new industry sector will need to be established. Component manufacturers were found to be suitable for membership of this new industry sector, however it is possible that a new type of organisation will emerge, possessing the more generic knowledge required to overhaul a wider range of components. Overhauled, guaranteed reused components will be functionally equivalent to their new counterparts and their anticipated lower price level is considered likely to instigate the practice of widespread component reuse.

In conclusion, this survey has determined that the construction industry is receptive to the concept of reusable building services components and this proposal is considered a viable mechanism for achievement of the required services installation adaptability. However, industrial implementation of this proposal is currently impeded by a lack of understanding of the technical feasibility of manufacturing reusable building services components and the economic viability of implementing their reuse process. Further work is therefore necessary to investigate these aspects of the proposal and to disseminate findings to the construction industry. This future work will investigate the potential role of provisions such as the adoption of life cycle design techniques and increased component standardisation and modularisation and design for disassembly in the delivery of reusable building services components to industry.

\section{References}

Department of Health (1996a), Acute Care at Home - Estate Implications (Health Facilities Note, No. 12), HMSO, London.

Department of Health (1996b), Re-engineering the Facilities Management Service (Health Facilities Note, No. 16), HMSO, London.

Duffy, F., et. al. (1993), The Responsible Workplace: The Redesign of Work and Offices, Butterworth Architecture, Oxford.

Lund, R. T., et. al. (1980), Energy Savings Through Remanufacturing: A Pre-Demonstration Study - Interim Progress Report, Center for Policy Alternatives Report Number 80-6, Massachusetts Institute of Technology, Cambridge, MA. 
Regan, C., McCall, M.R. (1997), The Reuse Market - Is It Worth It? (Paper No. SPE 38516),

Proceedings of Offshore Europe 97, 9-12 September, Aberdeen, UK, Society of Petroleum Engineers.

Siuru, B. (1990), "From Scrap Heap to Showroom", Mechanical Engineering, Vol. 112, No. 11, pp. 63-65.

Webb, R. S., et. al. (1997a), "Building Services Component Reuse: An FM Response to the Need for Adaptability", Facilities, Vol. 15, No. 12/13, pp. 316-322.

Webb, R. S., et. al. (1997b), Designing for Short Life: A Study into the Development of Reusable Packaged Building Services Components in the Healthcare Sector, Cobra '97 Conference, 10-12 September, University of Portsmouth, UK, The Royal Institution of Chartered Surveyors. 